\title{
Patterns of Skilled Birth Attendant Service Utilization and Its Determinants: A Cross Sectional Study in Southern Ethiopia
}

\author{
Shifera Asfaw ${ }^{1}{ }^{*}$, Tsion Assefa ${ }^{1}$, Addisu Tesfaye $^{2}$, Abebe Mamo ${ }^{1}$ \\ ${ }^{1}$ Department of Health Education and Behavioural Science, College of Public Health and Medical Sciences, Jimma University, Ethiopia \\ ${ }^{2}$ Engine, Project Field Coordinator, Jimma University, Ethiopia
}

Email address:

shiferaa@yahoo.com (S. Asfaw)

${ }^{*}$ Corresponding author

\section{To cite this article:}

Shifera Asfaw, Tsion Assefa, Addisu Tesfaye, Abebe Mamo. Patterns of Skilled Birth Attendant Service Utilization and Its Determinants: A Cross Sectional Study in Southern Ethiopia. Science Journal of Public Health. Vol. 4, No. 5, 2016, pp. 415-421. doi: $10.11648 /$ j.sjph.20160405.18

Received: March 10, 2016; Accepted: March 24, 2016; Published: September 2, 2016

\begin{abstract}
Pregnancy and child birth complications are a leading cause of death and disability among women of reproductive age in many developing countries. In Ethiopia the level of maternal mortality and morbidity are among the highest in the world. Increasing the proportion of deliveries with skilled attendants is being advocated as the most important step in preventing maternal and neonatal deaths. So, this study aims to assess skilled birth attendant service utilization and its determinant factors among mothers who gave birth within the last 12 months preceding the survey in Yeki district, Southern Ethiopia, 2014. Community based cross sectional study was conducted in Yeki district southern Ethiopia from March 30, to April 28, 2014. Stratified random sampling technique was used to select study participants from study areas and pre tested and structured questionnaire was used to collect the data. Data was analyzed using SPSS version 20 statistical software package used to present the descriptive statistic. Bivariate and multivariate analyses were conducted to identify factors associated to skilled birth attendant service utilization. A total of 304 mothers were involved in this study with $99.6 \%$ response rate. Only Eighty (26.32\%) of mothers were assisted by skilled health care providers during last child birth. The utilization of Skilled birth attendant service was significantly associated with residency of being living in urban area ( $\mathrm{AOR}=4.67,95 \% \mathrm{CI}$ : $1.64,13.24)$, exposure status about skilled birth attendant information through radio ( $\mathrm{AOR}=3.7,95 \% \mathrm{CI}: 1.33,10.3$ ), ANC visit during last pregnancy $(\mathrm{AOR}=3.52,95 \% \mathrm{CI} ; 1.18,10.44)$, having history of obstetric difficulty $(\mathrm{AOR}=2.5,95 \% \mathrm{CI}: 1.98,12.39)$ at $\mathrm{p}<0.05$. This study refines information on prevalence and predictors for skilled birth attendant service utilization. Residential area, status about skilled birth attendant information through radio, ANC visit during last pregnancy, and history of obstetric difficulty were factors associated with skilled birth attendant service utilization. The study implies that the government and nongovernmental organization should strengthen ANC visit and work on behavioural change communications to increase the uptake of maternal health service utilization.
\end{abstract}

Keywords: Skilled Attendant, Maternal Health Service Utilization, Mothers

\section{Introduction}

Skilled care is the care provided to a woman and her newborn during pregnancy, childbirth and immediately after birth by an accredited and competent health care provider who has at her/ his disposal the necessary equipment and the support of a functioning health system [1]. Proper medical attention and hygienic conditions during delivery can reduce the risk of complications and infections that can cause the death or serious illness of the mother and the newborn baby [2]. Pregnancy and child birth complications are a leading cause of death and disability among women of reproductive age in the developing countries of the world [3].

Globally, an estimated 287, 000 maternal deaths from complications of pregnancy and child birth occurred in 2010, the MMR in developing regions was 15 times higher than in 
developed regions even though MMR decline in Sub-Saharan Africa by $56 \%$ from levels in 1990 [4]. In addition to maternal death 300 million women in the developing world suffer from short and long-term illness related to pregnancy and childbearing [5].

Ethiopia has among the highest maternal mortality ratios (MMR) in the world, estimated 676 per 100,000 live births for the seven year period preceding the survey which is not significantly different from Ethiopian demographic and health survey (EDHS) 2005 report (673 per 100,000 live births). More than $60 \%$ of maternal deaths occur in the postpartum period. Of these, $45 \%$ occur within one day of delivery and more than $80 \%$ within two weeks after delivery [6].

Skilled attendance during labor, delivery and the early post-partum period could reduce an estimated $16-33 \%$ of maternal deaths. But, globally about $34 \%$ of the mothers deliver with at home without the help of skilled professional which result for 45 million births to be occurring at home [7, 8]. In Ethiopia, out of estimated 2.9 million deliveries annually, it is approximate 2.6 million occur at home. [9], only $10 \%$ of Ethiopian woman gives births at health facility, Twenty eight percent of mothers delivered by traditional birth attendants; while the majority of births were attended by a relative or some other person $(61 \%)$ and $5 \%$ of all births were delivered without any type of assistance at all. $[6,10]$.

The current number of skilled attendants is critically insufficient, an estimated 700000 midwives are needed worldwide to ensure universal coverage with maternity care, but there is currently a 50\% shortfall. In addition, 47000 doctors with obstetric skills are required, particularly in rural areas [11]. According to recent estimates, Ethiopia has one of the largest gaps in the midwifery workforce needed to reach the MDG5 target of skilled birth attendance by 2015 at a gap of 19,489 midwives [12].

Beside low number of skilled health professional there are many reasons for uneffective utilization of health service, some researcher mentions distance from health institution, friendliness of the service are a mentioned as a likely reasons [6].

However, studies concerning the issue are scarce in Ethiopia, particularly in remote areas like Yeki district of southern Ethiopia. Few existing studies tend to be urban and institution based, and they exclusively focused on magnitude of maternal services utilization. But detailed descriptions of the predictors of skilled birth attendant within its level of influence from different actors are not well studied yet.

Its facts that, addressing maternal health should encompass social, health communication and health systems. Therefore, the current study is community based, assessing the problem from multiple level of behavioural influence using a valid conceptual frame work which helps to meticulously identify the determinant factors of skilled birth service utilization in Yeki district.

\section{Methods and Materials}

\subsection{Study Area and Period}

The study was conducted in Yeki district between March
30 and April 28, 2014. Yeki is one of the districts of southern Ethiopia which is $525 \mathrm{kms}$ away from Addis Ababa, capital city of Ethiopia. Yeki district contains a total of 25 sub-districts, having total population 159,506 of which 78,158 are males; 81,348 are females with 34676 households. The health care delivery within the district is carried out by 6 health centers, 22 health posts, and one under construction district hospital with a total of 111 health professionals (including 8 Health officers, 11 midwife nurses, 50 nurses, 42 Health Extension Workers). This study was conducted among randomly selected mothers who gave births within the last twelve months prior to the data collection period and who were resident of the district. The sample size was calculated using single population proportion formula $\left.\left[(\mathrm{n}=(\mathrm{Z} 1-\alpha) / 2) \mathrm{p}(1-\mathrm{p}) / \mathrm{d}^{2}\right)\right]$ using a prevalence rate of skilled birth attendant $(\mathrm{p})$ is $10 \%$ (Ethiopian Demography Health Survey 2011 Report), 5\% of marginal error (d) and 95\% confidence level, design effect of 2 and $10 \%$ non response rate yields final sample size of 305 respondents who are potentially included in the interview.

\subsection{Sampling Techniques and Procedure}

Out of twenty five sub districts, eight of them were included using simple random sampling techniques. In each sub districts, first preliminary census was conducted to identify the targeted mothers who gave birth within last 12 months (source population) for the study. The total sample size was distributed to each kebele based on proportional to population size allocation. Using the sampling frame from the census results, study participants were selected by simple random sampling from each selected sub districts.

\subsection{Instrument and Measurement}

Data collection instrument was adapted from EDHS 2011 national level survey questionnaires, and items also taken from literatures which have similar objective. Structured questionnaires consist of seven parts mainly; socio-demographic variables, exposure to health information with "yes" "no" response, obstetric characteristics, skilled birth care utilization, knowledge with "yes" "no" and attitude on obstetric risk using likert scales used. Regarding Exposure status to health information, it was measured by "the extent to which mothers (respondent) have encountered specific messages or health information" [13], It was measured by self-report exposure of respondent to the mass communication (media) and exposure to health information (health talks) on utilization of skilled care during last pregnancy. Those respondents exposure at least to one of health information from TV, radio medical pamphlet, health providers health talk on utilizing skilled care during last pregnancy was considered as exposed to health information otherwise not exposed. ${ }^{6}$ skilled attendant is people with midwifery skills (doctors, midwives, and nurses) who have been trained to manage normal delivery diagnose and make refer obstetric complication. In this research, skilled attendant is measured 
by asking the mother whether or not assisted by Doctor, H. O, nurse, midwifery by their last delivery [1].

\subsection{Data Collection Techniques}

Data collection was carried out using structured questionnaires filled by data collectors through face to face interview. Eight trained Data collectors who were speak local language of the respondents recruited. Training was given for data collectors on data collection, interview skills, asking questions in a neutral manner. Two supervisors were assigned to monitor the data collection procedures. For all data collectors and supervisors one day training was given on briefing data collection instrument, interview technique and importance of taking informed consent before real data collection process starts. Each day data were checked for completeness and consistency.

\subsection{Statistical Analysis of the Data}

All filled questionnaires were checked for completeness and consistency, double data entry was made using Epi-data 3.1 software. Then the data were exported to SPSS statistical package version 20 for further analysis. Frequencies, proportion and summary statistics were used to describe the study participants in relation to significant variables and presented by using tables afterwards; bivariate analysis was carried out to identify candidate variables for the multivariable regression analysis. Finally, to identify the independent predictors of skilled birth attendant service utilization, only variables that were significantly associated in the bivarariate analysis were entered into multivariate regression modes. In the first regration model, those variables significance at individual label with $(\mathrm{P}<0.05)$ entered to final model to assess their predicting power to the outcome variable. Interactions between different variables were checked and co linearity diagnostics was done by checking the variance inflation factor. All tests were two sided and $\mathrm{P}<0.05$ was considered statistically significant. We report the result as odds ratios (ORs) with 95\% confidence interval.

\subsection{Ethical Clearance}

Letter of Ethical clearance was obtained from Research Ethics Committee of Jimma University. Formal letter of permission was endorsed from administrative bodies of the districts and then to the respective sub districts. Moreover, confidentiality was assured for the information provided since the name of study participants were not stated on the questionnaire rather coding system was applied. Before starting the interview, the respondents were requested for their verbal consent to participate in the study. And also the purpose of the study was explained to the study participants. Finally, all data accessed were kept confidential and it will remain so throughout the project period and thereafter.

\section{Result}

\subsection{Socio-demographic Characteristics of Study Population}

A total of 304 mothers who gave birth in last 12 month were interviewed with 99.6 response rate. The mean age of the respondents was $28.1 \pm 5.937 \mathrm{SD}$. Regarding to ethnic group of respondents, the rest 93 (30.6\%) were Amhara followed by Shekacho, Kaficho. Regarding to religion of respondents more than half $164(53.9 \%)$ were Orthodox Christians followed by Muslim and protestant.

Concerning marital status, 296 (97.4\%) of the women were currently married. Coming to mother education level, 86 $(28.3 \%)$ can't read and write, $49(16.1 \%)$ can read write, 115 $(37.8 \%)$ primary education and $54(17.8 \%)$ were attended up to secondary education and above. (Table 1)

Table 1. Socio-demographic characteristics of mothers $(n=304)$ who gave birth in last 12 months prior to study period in Yeki District, South Ethiopia may, 2014.

\begin{tabular}{|c|c|c|}
\hline Variable & Frequency & Percent \\
\hline \multicolumn{3}{|c|}{ Age at interview(mean, SD. $28 \pm 6$ yrs) } \\
\hline $15-19$ & 17 & 5.6 \\
\hline $20-24$ & 82 & 27 \\
\hline $25-29$ & 94 & 30.9 \\
\hline $30-34$ & 59 & 19.4 \\
\hline $35+$ & 52 & 17.1 \\
\hline \multicolumn{3}{|l|}{ Place of residence } \\
\hline Urban & 51 & 16.8 \\
\hline Rural & 253 & 83.2 \\
\hline \multicolumn{3}{|l|}{ Religious group } \\
\hline Orthodox Christian & 164 & 53.9 \\
\hline Muslim & 95 & 31.2 \\
\hline Protestant & 41 & 13.5 \\
\hline Traditional & 4 & 1.3 \\
\hline \multicolumn{3}{|l|}{ Marital status } \\
\hline Married & 296 & 97.4 \\
\hline Divorced & 6 & 2.0 \\
\hline Never married & 2 & .7 \\
\hline \multicolumn{3}{|l|}{ Ethnic group } \\
\hline Amahara & 93 & 30.6 \\
\hline Shekicho & 65 & 21.4 \\
\hline Keficho & 46 & 15.1 \\
\hline Sheko & 44 & 14.5 \\
\hline *Others & 56 & 18.4 \\
\hline \multicolumn{3}{|l|}{ Level of mother education } \\
\hline Primary education(1-8) & 115 & 37.8 \\
\hline Can't read and write & 86 & 28.3 \\
\hline secondary education and above & 54 & 17.8 \\
\hline Can read and write & 49 & 16.1 \\
\hline \multicolumn{3}{|l|}{ Occupation of mother } \\
\hline House wife & 212 & 69.7 \\
\hline Farmer & 69 & 22.7 \\
\hline Employee** & 12 & 4.0 \\
\hline Marchant & 11 & 3.6 \\
\hline \multicolumn{3}{|l|}{ Husband level of education } \\
\hline Primary education & 115 & 38.9 \\
\hline No formal education & 96 & 32.4 \\
\hline secondary and above & 85 & 28.7 \\
\hline \multicolumn{3}{|l|}{ Husband's occupation } \\
\hline Farmer & 247 & 83.4 \\
\hline Employee*** & 23 & 7.7 \\
\hline
\end{tabular}




\begin{tabular}{lll}
\hline Variable & Frequency & Percent \\
\hline Daily laborer & 11 & 3.7 \\
Merchant & 15 & 5.1 \\
\hline
\end{tabular}

Others *include Oromo, Mezengir, Gurage.

Employee** Gov't employee 7 (2.3\%), Private employee $5(1.7 \%)$

Employee*** Gov't employee 14 (4.7\%), Private employee 9(3\%)

\subsection{Obstetric Characteristics of the Respondents}

The distribution of the respondents by age at marriage; majority of mothers $222(73.5 \%)$ of the mothers were get married at age between 15-19 years and the rest $70(23.2 \%)$ of the mothers were married at age of twenty and above. More than half of mothers $171(56.2 \%)$ were got pregnant for first time at age of 15-19 years and the rest $128(42.1 \%)$ of mothers became pregnant for first time at their age of twenty and above. One hundred seventy one $(63.5 \%)$ of the mothers have two to four times experience of pregnancy and the rest 46(15.1\%) mothers were pregnant for five times and more. (Table 2).

Table 2. Obstetrics characteristics of mothers $(n=304)$ who gave birth in last 12 months prior to study period in Yeki district, Southern Ethiopia may, 2014.

\begin{tabular}{lll}
\hline Variable & Frequency & Percent \\
\hline Age at first marriage & & \\
$15-19$ & 222 & 73.5 \\
$20+$ & 70 & 23.2 \\
$<15$ & 10 & 3.3 \\
Age at 1st pregnancy & & \\
$15-19$ & 171 & 56.2 \\
$20+$ & 128 & 42.1 \\
$<15$ & 5 & 1.6 \\
No. of total pregnancy (Gravida) & & \\
1 & 65 & 21.4 \\
$2-4$ & 193 & 63.5 \\
$>=5$ & 46 & 15.1 \\
No. of total births (Para) & & \\
1 & 65 & 21.4 \\
$2-4$ & 199 & 65.5 \\
$>=5$ & 40 & 13.2 \\
ANC visits of last pregnancy & & \\
Yes & 231 & 76.0 \\
No & 73 & 24.0 \\
Frequency of ANC visit & & \\
1 & 279.3 \\
$2-4$ & 41 & 17.7 \\
$>=5$ & 176 & 76.2 \\
History of obstetric difficulty & & \\
Yes & 25 & \\
No & & \\
\hline & & \\
\hline
\end{tabular}

\subsection{Exposure Status to Health Information}

One hundred ninety two $(63.2 \%)$ were reported that, they were exposed an information about skilled birth care utilization during their last pregnancy given by health providers (health extension worker, nurse, midwife, and physician). From those respondents exposed to health information one hundred thirty $(68.1 \%)$ of them exposed two to four times during last pregnancy. From all respondent, Ninety two $(30.3 \%)$ mothers were reported their exposure to skilled birth care service information through radio during their last 12 month pregnancy period. (Table 3).
Table 3. Mothers exposure to health information in Yeki District, Southern Ethiopia may, 2014. $(n=304)$.

\begin{tabular}{lll}
\hline Variable & Frequency & Percent \\
\hline Exposure to radio & & \\
Yes & 92 & 30.3 \\
No & 212 & 69.7 \\
$\begin{array}{l}\text { Exposure to television } \\
\text { Yes }\end{array}$ & 30 & 9.9 \\
No & 274 & 90.1 \\
Exposure to health information last pregnancy & & \\
Yes & 192 & 63.2 \\
No & 112 & 36.8 \\
$\begin{array}{l}\text { Frequency of health information during last } \\
\text { pregnancy }\end{array}$ & & \\
$\begin{array}{l}\text { Once } \\
\text { Two-four }\end{array}$ & 19 & 9.4 \\
five and more & 130 & 68.1 \\
Common source of health information & 43 & 22.5 \\
$\begin{array}{l}\text { Medical(HEW, nurse, Dr) } \\
\text { People(friends, mother, relatives, neighbor) }\end{array}$ & 153 & 50.3 \\
\hline
\end{tabular}

\subsection{Knowledge of Respondent about Pregnancy, Labor and Delivery Service}

One hundred thirty five (44.4\%) mothers were aware of the risks of pregnancy who can at least mention a single risk. 174(57.2) mothers knows at least one danger sign of labor whereas, $177(58.2 \%)$ of mothers knows the risks of giving birth at home without skilled birth attendant. (Table 4).

Table 4. Knowledge of respondents toward pregnancy, labor and delivery service among mothers $(n=304)$ who gave birth in last 12 month prior to study period in Yeki District, South Ethiopia may, 2014.

\begin{tabular}{ll|l}
\hline Variable & Frequency & Percent \\
\hline Know risks of pregnancy & & \\
Yes & 135 & 44.4 \\
No & 169 & 55.6 \\
Knowing danger signs of pregnancy & & \\
Yes & 178 & 58.6 \\
No & 126 & 41.4 \\
Know labor danger signs & & \\
Yes & 174 & 57.2 \\
No & 130 & 42.8 \\
Know risks of home delivery & & \\
Yes & 177 & 58.2 \\
No & 127 & 41.8 \\
\hline
\end{tabular}

\subsection{Skilled Birth Attendant Service Utilization}

Two hundred twenty four (73.7\%) of the women reported as they were not assisted by skilled health provider during last child birth while the rest $80(26.3 \%)$ of the mothers reported as they were assisted by skilled health care provider during their last child birth.

Regarding to the person attended last child birth of the mother, $110(36.2 \%)$ of mothers reported as they were assisted their last child birth by relatives (mothers, mothers in law, husband) where as 98 (32.2\%) of respondents reported as they were assisted by TBA during last child birth and 53 (16.8\%) of mother were assisted by nurse, $27(9.1 \%)$ by midwife, 14 $(5.3 \%)$ by rural health extension workers and 1 (0.3) by physician. The possible reasons mentioned by the respondents for not assisted by skilled health care provider or delivering at 
health facility during last child birth was, fifty eight (25.9\%) mothers' responded labor was smooth and short, 49 (21.8\%) mothers replied previous home delivery (non skilled home delivery) was normal, $47(21.0 \%)$ mothers need to be with relatives.

\subsection{Factors Associated with Skilled Birth Attendant Service Utilization}

The final model was constructed by using enter method on multiple binary logistic regression analysis. All variables which showed statistical association with p-value $<0.05$ during the bivariate analysis were entered to multivariate logistic regression analysis to identify independent predictors of skilled birth attendant service utilization. From all variables entered for analysis using enter method; residential area, history of ANC visit, exposure to health information through radio, history of obstetric difficulty, remained significantly after adjusting other variables entered for multivariate analysis.
Being attended by skilled health provider during child birth was 4.6 times more likely among mothers in living in urban area as compared to mother live in rural area ( $\mathrm{AOR}=4.67,95 \% \mathrm{CI}: 1.64,13.24)$. Mothers with history of antenatal care visit during last pregnancy were 3.5 times more likely to utilize skilled birth services as compared to those mothers who had no antenatal care follow up during last pregnancy, $(\mathrm{AOR}=3.52,95 \% \mathrm{CI} ; 1.18,10.44)$. Mothers those exposed to health information about skilled birth attendant or birth at health facility through radio were 3.7 times more likely to gave birth by skilled health provider than those mother not exposed to health information $(\mathrm{AOR}=3.7,95 \% \mathrm{CI}: 1.33,10.3)$. Mothers who had of obstetric difficulty during last pregnancy and labor were 2.5 times more likely to be assisted by skilled health care provider during child birth than those mothers with no history of obstetric difficulty during last child birth $(\mathrm{AOR}=2.5,95 \%$ CI 1.98, 6,39). (Table 5).

Table 5. Summary logistic regression analysis of the relative effect of explanatory variable on skilled birth attendant service utilizations in Yeki District, South Ethiopia may, 2014. $N=304$.

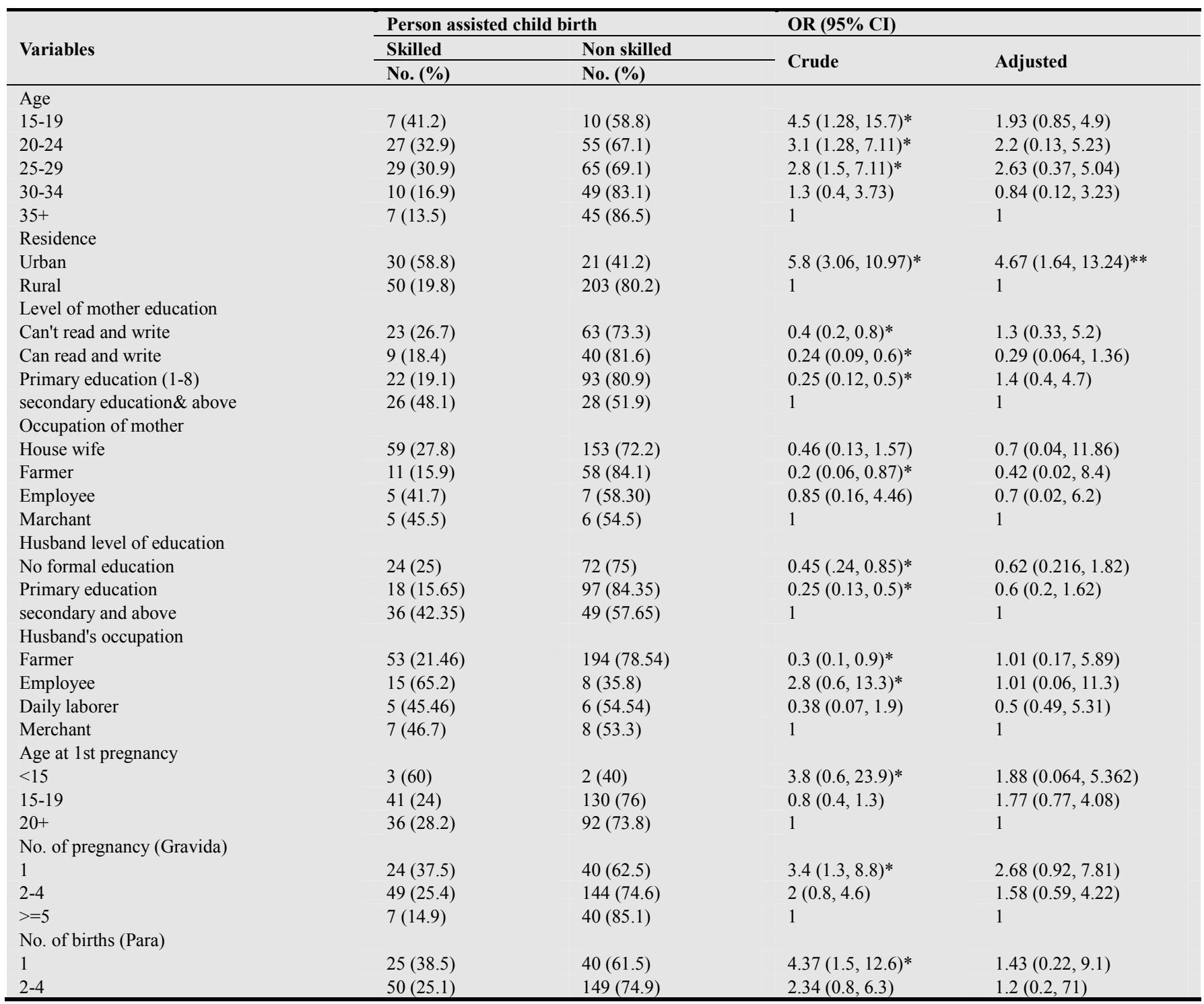




\begin{tabular}{|c|c|c|c|c|}
\hline \multirow{3}{*}{ Variables } & \multicolumn{2}{|c|}{ Person assisted child birth } & \multicolumn{2}{|l|}{ OR $(95 \%$ CI $)$} \\
\hline & Skilled & Non skilled & \multirow{2}{*}{ Crude } & \multirow{2}{*}{ Adjusted } \\
\hline & No. $(\%)$ & No. $(\%)$ & & \\
\hline$>=5$ & $5(12.5)$ & $35(87.5)$ & 1 & 1 \\
\hline \multicolumn{5}{|c|}{ ANC visits of last pregnancy } \\
\hline Yes & $74(32)$ & $157(68)$ & $5.26(2.2,12.6)^{*}$ & $3.52(1.18,10.44)^{* *}$ \\
\hline No & $6(8.2)$ & $67(91.8)$ & 1 & 1 \\
\hline \multicolumn{5}{|c|}{ Frequency of ANC visit } \\
\hline 1 & $7(17.1)$ & $34(82.9)$ & $0.14(0.03,0.7)^{*}$ & $0.12(0.05,2.65)$ \\
\hline $2-4$ & $60(34.1)$ & $116(65.9)$ & $0.4(0.1,1.6)$ & $0.65(0.06,1.74)$ \\
\hline$>=5$ & $7(50)$ & $7(50)$ & 1 & 1 \\
\hline \multicolumn{5}{|c|}{ History of obstetric difficulty } \\
\hline Yes & $11(44)$ & $14(56)$ & $2.4(1.03,5.5)^{*}$ & $2.5(1.98,6,39)^{* *}$ \\
\hline No & $69(24.8)$ & $210(75.3)$ & 1 & 1 \\
\hline \multicolumn{5}{|c|}{ Exposure status for health information through Radio } \\
\hline Yes & $40(43.5)$ & $52(56.5)$ & $3.3(2,5.6)^{*}$ & $3.7(1.33,10.3)^{* *}$ \\
\hline No & $40(18.9)$ & $172(81.1)$ & 1 & 1 \\
\hline \multicolumn{5}{|c|}{ Exposure to Television } \\
\hline Yes & $15(50)$ & $15(50)$ & $3.2(1.4,7)^{*}$ & $0.96(0.25,3.59)$ \\
\hline No & $65(23.7)$ & $209(76.3)$ & 1 & 1 \\
\hline \multicolumn{5}{|c|}{ Exposure to health talks at $\mathrm{HF}$} \\
\hline Yes & $63(32.8)$ & $129(67.2)$ & $2.7(1.5,5)^{*}$ & $1.52(0.12,2.35)$ \\
\hline No & $17(15.2)$ & $95(84.8)$ & 1 & 1 \\
\hline
\end{tabular}

* Statistically associated crude odd ratio at $\mathrm{p}<0.05$

** Statistically associated Adjusted odd ratio at $\mathrm{p}<0.05$

\section{Discussion}

The study shows that, eighty (26.3\%) of the participants were assisted by skilled health care provider during their last child birth. The current finding was higher than Ethiopian demographic and health survey in 2011 report where only $10 \%$ of mothers in the country utilized skilled birth care service [6]. And other similar Cross sectional studies done in Kenya also show that $48.2 \%$ mothers' give birth by skilled birth care provider [14]. This may be explained by the different in the scope of the study and geographical different between those studies. Cultural and economical difference among Ethiopian and Kenyan women also possible factors for the difference.

In this study, Factors identified to be determinants for skilled birth care service utilization includes residential place being rural and urban, history of antenatal care visit during last pregnancy, history of diagnosis of obstetric difficulty and exposure status for health to information through radio.

From the total urban resident study participants; 30 (58.8\%) mothers reported as they were assisted by skilled health care provider during last child birth where as only $50(19.8 \%)$ of rural mothers reported as they were assisted by skilled health provider, The study showed that urban women were four point six times more likely to utilize skilled birth services as compared to rural mothers. A report on Ethiopian demographic health survey also note that urban births are notably more likely than rural births to be delivered by skilled health care (50\% Vs 4\%) [6]. Its implies that in urban areas the proportion of mothers with education might be higher, accessibility of the services with minimal distance might be granted, issue of easily access for transportation may be arranged. Other possible meaning of this study is mothers living in urban area could have better knowledge of pregnancy and delivery complications, and better access to health information than rural mothers.

The current study also showed that Being exposed to skilled care health information through radio were about four times more likely to gave birth by skilled health care provider as compared to those mothers with no exposure to health information through radio. Other study conducted south Ethiopia also show that those participant who listen health information through radio is more likely to use the skilled health services than those who never exposed to the information [15]. This implies that exposure for health information through highly reachable media like radio increase the awareness of the mother about benefit of skilled attended thereby augment utilization rate of skilled health care delivery service.

This study revealed that ANC visit during their last pregnancy and which showed statistically significant association with skilled birth attendant service utilization. Mothers with ANC visit during their last pregnancy were three and a half times more likely to utilize skilled birth services as compared to those mothers, who had no ANC visit during last pregnancy, Other study conducted north west of Ethiopia also show that mothers who visited ANC during last pregnancy were four times more likely to deliver in health facilities than mothers who did not visit ANC during last pregnancy[10]. The possible explanation for this finding may be, mothers who had antenatal care follow up could receive advice and health education about pregnancy related complications and advantages of giving birth by skilled birth care provider. These enhance the mothers' decision making ability to use skilled delivery services.

This study showed that mothers who had history of obstetric difficulty during last pregnancy and labor were two and half times more likely to be assisted by skilled health care provider during child birth than those mothers with no history 
of obstetric difficulty during last child birth. Other cross sectional studies at Dodota district of Ethiopia reported that mothers utilization of health care for delivery was significantly associated with the length of previous labor and other obstetrics difficulty [16]. As the length of labor prolonged in the previous delivery the woman prefers to deliver in health institution, the same is true when a woman had other difficulties during their previous labors.

This might be explained due to; mothers who face obstetrics difficulty during last delivery may develop perceived high threat for delivering without skilled attendant. This will influence them to use skilled attendant to avoid the threat.

\section{Conclusion and Recommendation}

This study has revealed that skilled birth attendant service utilization by mothers was a little bit low which (26\%), while large proportion (74\%) of mothers gave their last child birth without assistance of skilled birth attendant despite (76\%) had ANC visit during their last pregnancy. Nearly half respondents had not knowledgeable towards danger sign of pregnancy, labour, advantage of skilled care and disadvantage of home birth. Place of residence, antenatal care follows up, histories of obstetric difficulty during last pregnancy and exposure to health information through radio were found to be independent determinants for skilled birth attendant service utilization. So reinforcement activities like soap and baby wear for mothers who had ANC visit and gave birth at health centers.

This is a gigantic gape that the government and other actors who work on maternal health issue should intervene urgently. Regional and district health bureau of the southern Ethiopian should consider mass media preparing radio spot on skilled care utilization using local language. Interventional program such as educating mothers on skilled care at community-based including at house hold by health extension worker should be strengthen to clear up awareness problem in the area of danger sign of pregnancy, labor, advantage of skilled care and disadvantage of home birth. Innovative culturally sound communication strategies should also develop by national and regional health communication officer to encourage skilled health care service utilization. It also compulsory to strengthening antenatal care service that will be critical to improve skilled birth assistance during child birth.

\section{Acknowledgments}

We would like to express our heartfelt gratitude to our study participants. We also want to give thank for Yeki district health office for giving relevant information, guide and facilitation during our study period.

\section{References}

[1] WHO. Making pregnancy safer: the critical role of the skilled attendant, A joint statement by WHO, ICM and FIGO. Geneva; 2004.
[2] Bureau of Public Affairs Department Of State The Office of Electronic Information. Global Health Initiative: Ethiopia Strategy. 2011.

[3] Baral YR, Lyons K, Skinner J van TE. Determinants of Skilled Birth Attendants for Delivery in Nepal. Kathmandu Univ Med J. 2010; 8 (31): 325-32.

[4] UNFPA, UNICEF, WHO WB. Trends in Maternal Mortality:1990-2010. 2012 p. 44.

[5] World Health Organization. The world health report 2005-Make every mother and child count. Geneva.; 2005.

[6] Ethiopia Central Statistical Agency and ICF International. Ethiopia Demographic and Health Survey 2011. Addis Ababa, Ethiopia and Calverton, Maryland, USA; 2012 p. 452.

[7] Mulumebet Abera, Abebe G/mariam TB. Predictors of Safe Delivery Service Utilization in Arsi Zone, South-East Ethiopia. Ethiopian Journal of Health Sciences. 2011 Aug; 21 (1): 95-106.

[8] WHO, UNICEF, UNFPA and TWB. Maternal Mortality in 2005. 2007.

[9] Asheber GM. D. Report On the National Situational Analysis of Pre-Service Midwifery Training In Ethiopiaym a. 2008.

[10] Teferra AS, Alemu FM, Woldeyohannes SM. Institutional delivery service utilization and associated factors among mothers who gave birth in the last 12 months in Sekela District, North West of Ethiopia: A community - based cross sectional study. BMC Pregnancy and Childbirth. 2012 Jul;12 (1): 74.

[11] WHO. Department of Making Pregnancy Safer Department of Child and Adolescent Health and Development Department of Gender, Women and Health Department of Reproductive Health and Research, Skilled birth attendants fact sheet. Switzerland; 2008.

[12] Dynes M, Buffington ST, Carpenter M, Handley A, Kelley M, Tadesse L, et al. Strengthening maternal and newborn health in rural Ethiopia: Early results from frontline health worker community maternal and newborn health training. Midwifery. 2012; (0).

[13] Consumer Health Informatics Research Resource - Exposure [Internet]. [cited 2013 Jun 14]. Available from: file:///C:/Users/intel/Desktop/Arrange/exposure/Consumer Health Informatics Research Resource - Exposure.htm

[14] Carol Wanjira, Moses Mwangi, Evans Mathenge GM and ZN. Delivery Practices and Associated Factors among Mothers Seeking Child Welfare Services in Selected Health Facilities in Nyandarua South District, Kenya. BMC Public Health. 2011.

[15] Regassa N. Antenatal and postnatal care service utilization in southern Ethiopia: a population-based study. African Health Sciences. 2011 Sep; 11 (3): 390-7.

[16] Fikre AA, Demissie M. Prevalence of institutional delivery and associated factors in Dodota Woreda (district), Oromia regional state, Ethiopia. Reproductive health. 2012 Dec; 9 (1): 33. 